\title{
Environmental Air Pollution and the Risk of Osteoporosis and Bone Fractures
}

\author{
Vu H. Nguyen ${ }^{1,2}$ \\ ${ }^{1}$ Public Health Program, Department of Health Sciences, School of Health Professions, University of Missouri, Columbia, MO, USA; ${ }^{2}$ Community \\ Health Program, Nursing Department, School of Natural Sciences \& Mathematics, Columbia College of Missouri, Columbia, MO, USA
}

\section{Dear Editor,}

The study by Nakao et al. [1] presents important findings that bring necessary attention to the effects of the environmental factor of air pollution on human health, particularly chronic obstructive pulmonary disease (COPD) and its detrimental effects on health-related quality of life (HR-QoL). I would also like to bring attention to the effects of air pollution on other important human health concerns: osteoporosis and bone fractures. Similarly to COPD, having osteoporosis and experiencing bone fractures, especially hip fractures, significantly decreases HR-QoL [2]. In addition, a recent study has brought to light how osteoporosis and bone fractures can be caused by air pollution, and found that populations in areas of higher ambient concentrations of particulate matter less than $2.5 \mu \mathrm{m}$ had lower bone mineral density with higher rates of hospital admissions for bone fractures, which led to the conclusion that air pollution is a risk factor for osteoporosis and bone fractures [3]. Prada et al. [3] found that air polluted with particulate matter, such as black carbon, is harmful to bone health, al-

Received: May 22, 2018 Accepted: June 20, 2018

Corresponding author: Vu H. Nguyen, PhD

Public Health Program, Department of Health Sciences, School of Health Professions, University of Missouri, 802 Lewis Hall, Columbia, MO 65211, USA

E-mail: NguyenVH@health.missouri.edu

This is an Open Access article distributed under the terms of the Creative Commons Attribution Non-Commercial License (http://creativecommons.org/licenses/bync/4.0/) which permits unrestricted non-commercial use, distribution, and reproduction in any medium, provided the original work is properly cited. though they did not have access to data on other air pollutants such as nitrogen dioxide $\left(\mathrm{NO}_{2}\right)$ that Nakao et al. [1] found to have adverse effects on COPD. Nonetheless, another recent study by Chang et al. [4] found that air polluted with greater concentrations of $\mathrm{NO}_{2}$, along with carbon monoxide, in Taiwan did increase the risk of osteoporosis and bone fractures.

The reason why this is significant is because Korea-as well as many other parts of Asia-is already vulnerable to osteoporosis and bone fractures. Asian ethnicity is a commonly known risk factor for osteoporosis, and air pollution, particularly in areas with higher concentrations of traffic, further exacerbates the risk of this disease and its severe consequences. In fact, a recently published study by the Asian Federation of Osteoporosis Societies (AFOS) [5] projected that the number of bone fractures caused by osteoporosis, specifically hip fractures, will increase 2.28-fold within the next few decades in Asia (including an increase in Korea), and this will result in a 1.59-fold increase in health care costs. The AFOS concluded that osteoporosis and bone fractures remain a key public health issue in Asia, and that health policies in Asia should be aimed at prevention.

Therefore, as environmental air pollution has been shown to have adverse negative effects on COPD [1], this letter calls for additional attention to its harmful contributions to osteoporosis and bone fractures as well. Health policies aimed at improving environmental air quality will lead to the prevention of numerous diseases for better overall health in Korea, Asia, and the rest of the world. 


\section{CONFLICT OF INTEREST}

The author has no conflicts of interest associated with the material presented in this paper.

\section{ORCID}

Vu H. Nguyen http://orcid.org/0000-0001-5555-2994

\section{REFERENCES}

1. Nakao M, Ishihara Y, Kim CH, Hyun IG. The impact of air pollution, including asian sand dust, on respiratory symptoms and health-related quality of life in outpatients with chronic respiratory disease in Korea: a panel study. J Prev Med Public Health 2018;51(3):130-139.

2. Randell AG, Nguyen TV, Bhalerao N, Silverman SL, Sambrook
PN, Eisman JA. Deterioration in quality of life following hip fracture: a prospective study. Osteoporos Int 2000;11(5):460466.

3. Prada D, Zhong J, Colicino E, Zanobetti A, Schwartz J, Dagincourt N, et al. Association of air particulate pollution with bone loss over time and bone fracture risk: analysis of data from two independent studies. Lancet Planet Health 2017;1(8):e337e347.

4. Chang KH, Chang MY, Muo CH, Wu TN, Hwang BF, Chen CY, et al. Exposure to air pollution increases the risk of osteoporosis: a nationwide longitudinal study. Medicine (Baltimore) 2015; 94(17):e733.

5. Cheung CL, Ang SB, Chadha M, Chow ES, Chung YS, Hew FL, et al. An updated hip fracture projection in Asia: the Asian Federation of Osteoporosis Societies study. Osteoporos Sarcopenia 2018; 4(1):16-21. 